\title{
Karakteristik Risiko Kesehatan Non Karsinogen pada Remaja Siswa Akibat Pajanan Inhalasi Debu Particulate Matter $<2,5\left(\mathbf{P M}_{2,5}\right)$
}

\author{
Characteristic of Health Risks on Students Due to Dust Inhalation \\ Exposure of Particulate Matter $<2.5\left(P_{2,5}\right)$
}

\author{
Ony Rosalia ${ }^{1}$, Bambang Wispriyono ${ }^{2 *}$, Haryoto Kusnoputranto ${ }^{2}$ \\ ${ }^{1}$ Program Sarjana Kesehatan Masyarakat, Departemen Kesehatan Lingkungan FKM UI \\ ${ }^{2}$ Departemen Kesehatan Lingkungan, Fakultas Kesehatan Masyarakat Universitas Indonesia \\ (bwispri@ui.ac.id)
}

\begin{abstract}
ABSTRAK
Peningkatan kendaraan transportasi menyebabkan pencemaran udara. $\mathrm{PM}_{2,5}$ polutan utama memiliki pengaruh besar terhadap kesehatan non karsinogen. Kondisi cekungan Bandung menyebabkan polutan terperangkap karena penyebaran polutan terhambat. Penelitian bertujuan menganalisis risiko kesehatan pada remaja siswa SMPN 16 Bandung akibat pajanan inhalasi $\mathrm{PM}_{2.5}$ di lingkungan sekolah. Desain studi Analisis Risiko Kesehatan Lingkungan (ARKL). Pengukuran konsentrasi PM P. $_{2,5}$ dilakukan pada 10 titik menggunakan Haz Dust EPAM 5000. Sampel siswa kelas VIII sebanyak 66 siswa yang dipilih secara acak. Rata-rata konsentrasi PM $_{2,5}$ sebesar $(29,34$ $\left.\mu \mathrm{g} / \mathrm{m}^{3}\right)$, masih di bawah nilai baku mutu menurut PP Nomor 41 Tahun $1999\left(65 \mu \mathrm{g} / \mathrm{Nm}^{3}\right)$. Adanya peningkatan Intake realtime, 3 tahun dan 12 tahun secara berturut-turut $7.53 \times 10^{-5}, 1.25 \times 10^{-4}, 5.02 \times 10^{-4} \mathrm{mg} / \mathrm{kg} / \mathrm{hari}$. Intake $\mathrm{PM}_{25}$ tinggi pada siswa dengan berat badan rendah dibandingkan dengan siswa dengan berat badan yang besar. Estimasi risiko kesehatan dinyatakan sebagai Risk Quotient (RQ) yang dihitung dari rata-rata intake pajanan $\mathrm{PM}_{2,5}$ terhadap siswa dan dosis referensi $(R f C), \mathrm{RQ}>1$ menunjukkan risiko perlu dikendalikan. Hasil analisis dengan durasi pajanan realtime, 3 tahun, dan 12 tahun menunjukkan batas aman terhadap pajanan $\mathrm{PM}_{2.5}(\mathrm{RQ}<1)$. Secara keseluruhan siswa kelas VIII tidak berisiko terhadap pajanan inhlasi $\mathrm{PM}_{2,5}$ di lingkungan sekolah.
\end{abstract}

Kata kunci : PM2,5, remaja siswa, sekolah

\section{ABSTRACT}

Increase in transport vehicles causes air pollution. Major pollutant of $P M_{2.5}$ provides an enormous impact on health. Basin condition in Bandung causes the pollutants to be trapped because the pollutant cannot be released. The aim of this research is to analyze the health risks of junior high school students of SMPN 16 Bandung due to PM ${ }_{2.5}$ inhalation exposure in the school environment by using Environmental Health Risk Assessment method. PM ${ }_{2.5}$ concentration assessment was conducted at 10 points with a sample of 66 students' grade VIII selected randomly. The average concentration of $P M_{2.5}$, which was $29.34 \mu \mathrm{g} / \mathrm{m}^{3}$ was still below the standard value regulated by Government Regulation No. 41 of $1999\left(65 \mu \mathrm{g} / \mathrm{Nm}^{3}\right)$. The increased in real-time intake for 3 years and 12 years respectively were $7.53 \times 10^{-5}, 1.25 \times 10^{-4}, 5.02 \times 10^{-4} \mathrm{mg} / \mathrm{kg} /$ day. $P M_{25}$ intake was higher in students with light weight than students with heavy weight. Estimated health risks was expressed as risk quotient (RQ) calculated from the average of $P M_{2.5}$ exposure intake on students and reference dose (RfC), $R Q>1$ indicated the risk needed to be controlled. The results of the analysis with the duration of real-time exposure for 3 years and 12 years showed a safe limit to $P M_{2.5}$ exposure $(R Q<1)$. Overall grade VIII students are not at risk of $P M_{2.5}$ inhalation exposure in school environments.

Keywords : PM ${ }_{2 ., 5}$,junior high school students, school 


\section{PENDAHULUAN}

Pertumbuhan kegiatan transportasi dapat mempengaruhi penurunan kualitas lingkungan salah satunya berkontribusi terhadap terjadinya pencemaran udara. Polutan utama pencemaran udara meliputi $\mathrm{PM}, \mathrm{CO}, \mathrm{SO}_{2}, \mathrm{H}_{2} \mathrm{~S}, \mathrm{NO}_{2}, \mathrm{~Pb}$, ozon dan lain-lain. ${ }^{1}$ Target utama dari pencemaran udara adalah paru-paru. Beberapa gangguan terhadap paru-paru adalah asthma, bronchitis, pneumonia, Chronic Obstructive Pulmonary Disease) dan diperkirakan pecemaran udara membunuh 1 dari 8 orang di seluruh dunia, karena penyakit jantung, stroke, penyakit pernapasan dan kanker. ${ }^{2}$ Particulate Matter (PM) memiliki pengaruh besar terhadap kesehatan dari polutan lainnya. Menurut American Lung Association bentuk yang sangat berbahaya dari SPM adalah partikel halus $\left(\mathrm{PM}_{10}\right.$, dengan diameter rata-rata kurang dari 10 mikrometer) dan partikulat halus $\left(\mathrm{PM}_{2,5}\right.$ dengan diameter rata-rata kurang dari 2,5 mikrometer). ${ }^{3}$

$\mathrm{PM}_{2,5}$ merupakan polutan udara berbentuk partikel debu dengan ukuran diameter $\leq 2.5 \mu \mathrm{m}$, lebih kecil dari $1 / 30$ bagian dari rambut manusia dengan diamerer $70 \mu \mathrm{m} . \mathrm{PM}_{2,5}$ terdiri dari sulfat, nitrat, organic compounds, ammonium compounds, metal, material acidic. ${ }^{4}$ Hasil pengukuran satelit menujukkan bahwa ada peningkatan polusi partikel halus yang membentang dari Gurun Sahara di Afrika Utara ke Asia timur. Berdasarkan pengukuran satelit ini, WHO memperkirakan bahwa lebih dari $80 \%$ populasi global terkena dampak tidak sehat akibat polusi partikel halus (WHO menganggap konsentrasi partikel halus ratarata tahunan lebih dari $10 \mu \mathrm{g} / \mathrm{m}^{3}$ menjadi tidak sehat). ${ }^{5}$ Ada lima sumber spesifik $\mathrm{PM}_{2,5}$, yaitu sulfat, sisa minyak, lalu lintas, industri logam baja, dan tanah. ${ }^{6}$ Polusi udara partikulat sebagian besar terdiri dari partikel $\mathrm{PM}_{2,5}$ yang bertanggungjawab untuk 60,000-70,000 kematian prematur per tahun. ${ }^{3}$

Program healthy school dilaksanakan untuk mengurangi faktor risiko salah satunya terkait dengan kondisi kronis pada anak dan remaja di sekolah yang berhubungan dengan penyakit pernafasan yaitu asma karena sebagian besar waktu mereka dihabiskan di sekolah. Penelitian di Perancis membuktikan adanya korelasi positif peningkatan prevalensi asma dan rhinitis pada anak sekolah dengan konsentrasi $\mathrm{PM}_{2,5}$ yang tinggi di dalam kelas. ${ }^{7} \mathrm{PM}_{2,5}$ dalam ruang dipengaruhi oleh emisi kendaraan, kontribusi emisi kendaraan ditemukan lebih tinggi pada sekolah-sekolah yang terletak dekat dengan jalan raya daripada sekolah yang terletak pada jarak yang cukup dari jalan raya. Jenis kegiatan mempengaruhi kadar $\mathrm{PM}_{2,5}$ di wilayah tersebut. ${ }^{8}$

Pemantauan konsentrasi Black Carbon dan $\mathrm{PM}_{2,5}$ di beberapa kota besar di Indonesia dari bulan Januari-Desember 2011 didapatkan rata-rata konsentrasi $\mathrm{PM}_{2,5}$ dan black carbon untuk area Bandung $\left(\mathrm{PM}_{2.5}: 18,35 \mu \mathrm{g} / \mathrm{m}^{3}\right)$ dan Jakarta $\left(\mathrm{PM}_{2,5}: 16,50 \mu \mathrm{g} / \mathrm{m}^{3}\right)$ lebih tinggi dibandingkan dengan Yogyakarta $\left(\mathrm{PM}_{2,5}: 8.78 \mu \mathrm{g} / \mathrm{m}^{3}\right)$. Kondisi ini menunjukkan polusi yang terjadi di Bandung dan Jakarta lebih tinggi daripada di Yogyakarta. ${ }^{9} \mathrm{Ka}-$ jian Indeks Kualitas Lingkungan Hidup diketahui rerata konsentrasi $\mathrm{PM}_{10}$ di Bandung tahun 20122014 adalah $42,58 \mu \mathrm{g} / \mathrm{m}^{3}$ dengan rerata $\mathrm{PM}_{2,5}$ adalah $16,87 \mu \mathrm{g} / \mathrm{m}^{3}$. Hal ini berarti konsentrasi rerata tahunan untuk $\mathrm{PM}_{10}$ dan $\mathrm{PM}_{2,5}$ di Kota Bandung melebihi baku mutu lingkungan yang ditetapkan sesuai dengan PP No.41 Tahun 1990 yaitu $15 \mu \mathrm{g} /$ $\mathrm{Nm}^{3}$.

Meningkatnya pencermaran udara di Kota Bandung disebabkan oleh sektor transportasi dan kemudahan akses memasuki Kota Bandung. Data BPLH Kota Bandung menunjukan bahwa berdasarkan hasil uji emisi gas buang kendaraan bermotor tahun 2002 - 2005 lebih dari 60\% kendaraan berbahan bakar solar tidak memenuhi baku mutu emisi, sementara untuk yang berbahan bakar bensin berfluktuasi dari sekitar 10\% hingga 52\%. Dinas Perhubungan Kota Bandung mengemukakan bahwa angkutan kota adalah penyumbang polusi udara yang paling besar. Meningkatnya pencemaran udara berdampak terhadap penurunan derajat kesehatan. Pada tahun 2011 ISPA menjadi salah satu penyebab kematian balita di Kota Bandung.

Salah satu sekolah di Bandung yaitu Sekolah Menengah Pertama (SMP) Negeri 16 Bandung yang berlokasi di Jl. PH. H. Mustofa No.53 Neglasari, Cibeuyiung Kaler, merupakan sekolah yang lokasinya berada dipinggir jalan raya dengan lalu lintas yang padat dan berdekatan dengan Stasiun Pengisian Bahan Bakar Umum (SPBU) sehingga memiliki risiko paparan partikulat terhadap penghuni sekolah khsusunya siswa. Penelitian mengenai analisis risiko pajanan $\mathrm{PM}_{2,5}$ di udara terhadap 
anak sekolah masih jarang dilakukan di Indonesia. Untuk itu perlu dikaji risiko kesehatan non karsinogen pada anak sekolah akibat pajanan inhalasi debu $\mathrm{PM}_{2,5}$ di lingkungan sekolah.

\section{BAHAN DAN METODE}

Penelitian menggunakan metode studi Analisis Risiko Kesehatan Lingkungan (ARKL), tujuaanya untuk mengetahui tingkat risiko kesehatan yang diterima siswa di sekolah akibat pajanan inhalasi $\mathrm{PM}_{2.5}$. Langkah studi ARKL adalah identifikasi bahaya, analisis dosis respon, analisis pemajan, karakteristik risiko. Berikut rumus yang digunakan dalam penelitian:

Penilaian Intake

$$
\text { Intake }=\frac{C \times R \times t_{E} \times f_{E} \times D t}{W b \times \operatorname{tavg}}
$$

\section{Perhitungan Tingkat Risiko Non Karsinogen}

$$
R Q=\frac{I_{n k}}{R f C}
$$

Lokasi penelitian dilakukan di SMPN 16 Bandung yang terletak di Jl. PH. H. Mustofa No.53 Neglasari, Cibeuyiung Kaler Kota Bandung. Penelitian ini dilakukan pada bulan AprilMei 2017. Populasi dalam penelitian ini adalah remaja siswa kelas VIII di SMPN 16 Bandung. Sampel dalam penelitian ini siswa kelas VIII di SMPN 16 Bandung yang telah memenuhi kriteria inklusi dan ekslusi.Besar sampel sebanyak 66 siswa, metode pemilihan sampel yang digunakan dalam penelitian ini adalah systematic random sampling. Siswa yang dijadikan responden adalah siswa yang kelasnya terpilih untuk dilakukan pengukuran $\mathrm{PM}_{2,5}$ yaitu sebanyak 4 kelas yaitu kelas VIII A, kelas VIII C, kelas VIII F dan kelasVIII I.

Pengukuran konsentrasi $\mathrm{PM}_{2,5}$ dilakukan pada 10 titik yaitu 1 titik di gerbang utama, 1 titik dipintu masuk ke area bangunan sekolah, 4 titik di koridor kelas, dan 4 titik di dalam kelas. Lama pengukuran selama 60 menit. Pengukuran $\mathrm{PM}_{2.5}$ dilakukan dengan menggunakan alat sampel digital direct reading Haz Dust EPAM 5000 USA. Data antropometri dan pola aktivitas siswa didapatkan melalui pengukuran dan wawancara langsung. Semua data hasil penelitian dimasukkan ke dalam tabel untuk menghitung nilai minimum, maksimum dan standar deviasi. Kemudi- an melakukan uji kenormalan data (One-Sampel Kolmogrov-Smirnov Test) untuk variabel konsentrasi $\mathrm{PM}_{2,5}$ berat badan, lama pajanan, durasi pajanan dan frekuensi pajanan. Data yang berdistribusi normal $(p>0,05)$ nilai yang digunakan adalah rata-rata (mean), sedangkan data yang tidak berdistribusi normal $(\mathrm{p}<0,05)$ nilai yang digunakan adalah nilai tengah (median) menggunakan aplikasi SPSS. Selanjutnya menghitung intake yang diterima oleh siswa dan tingkat risiko pajanan $\mathrm{PM}_{2,5}$ terhadap siswa.

\section{HASIL}

Karakteristik umur siswa yang ikut dalam penelitian sudah masuk dalam kriteria inklusi penelitian yaitu antara $\geq 13-\leq 15$ tahun. Hasil penelitian diketahui bahwa siswa yang berusia 13 tahun sebanyak 11 siswa, usia 14 tahun sebanyak 53 siswa dan berusia 15 tahun ada 2 siswa. Jumlah responden laki-laki yaitu sebesar $40,9 \%$, sedangkan responden perempuan sebesar 59,1\%. Tabel 1 menunjukkan siswa yang berangkat ke sekolah dengan berjalan kaki lebih banyak yaitu 45,5\% dan yang menggunakan angkutan umum lebih sedikit hanya sebesar $22,7 \%$. Hal ini dikarenakan sebagian besar siswa kelas VIII tinggal dekat dengan sekolah. Hasil analisis jarak rumah dengan sekolah didapatkan rata-rata jarak rumah dengan sekolah sejauh $1,5 \mathrm{~km}$, jarak paling dekat yaitu $0,1 \mathrm{~km}$ dan terjauh $7 \mathrm{~km}$. Siswa yang sudah merokok ada sebanyak $7,6 \%$ siswa, berdasarkan hasil wawancara usia mulai merokok yaitu pada usia 13 tahun dengan jumlah batang rokok yang dihisap sebanyak 1-2 batang per hari. Tabel 2 menunjukkan juga bahwa status merokok di dalam anggota keluarga sebanyak $81,8 \%$ dan yang paling besar adalah ayah sebanyak $45(68,2 \%)$. Berdasarkan Tabel 2 siswa yang tidak memiliki riwayat sesak nafas dalam 2 minggu terakhir lebih banyak daripada siswa yang memiliki gangguan sesak nafas yaitu sebanyak $87,9 \%$. Siswa yang tidak memiliki gangguan batuk dalam 2 minggu terakhir sebanyak $69,7 \%$. Namun, yang mengaku pernah mengalami gangguan pernafasan selama bersekolah di SMPN 16 Bandung lebih banyak yaitu sebesar $54,5 \%$.

Konsentrasi $\mathrm{PM}_{2,5}$ tertinggi berada pada titik gerbang masuk depan sebesar $49,3 \mu \mathrm{g} / \mathrm{m}^{3}$, sedangkan konsentrasi terkecil berada pada titik koridor kelas VIII F sebesar 15,73 $\mu \mathrm{g} / \mathrm{m}^{3}$. Untuk konsen- 
Tabel 1. Gambaran Kendaraan yang Digunakan Siswa

\begin{tabular}{lcccc}
\hline \multirow{2}{*}{\multicolumn{1}{c}{ Variabel }} & \multicolumn{2}{c}{$\begin{array}{c}\text { Kendaraan Berangkat } \\
\text { Sekolah }\end{array}$} & \multicolumn{2}{c}{$\begin{array}{c}\text { Kendaraan Pulang } \\
\text { Sekolah }\end{array}$} \\
\cline { 2 - 5 } & $\mathbf{n}$ & $\mathbf{\%}$ & $\mathbf{n}$ & $\mathbf{\%}$ \\
\hline Berjalan Kaki & 30 & 45,5 & 43 & 65 \\
Kendaraan Motor Pribadi & 21 & 31,8 & 4 & 6,1 \\
Angkutan Umum & 15 & 22,7 & 1 & 27,3 \\
\hline
\end{tabular}

Sumber : Data Primer, 2017

Tabel 2. Status Merokok Siswa Kelas VIII SMPN 16 Bandung

\begin{tabular}{|c|c|c|}
\hline \multirow{2}{*}{ Variabel } & \multicolumn{2}{|c|}{$\mathbf{n}(\%)$} \\
\hline & Ya & Tidak \\
\hline Kebiasaan Merokok & $5(7,6 \%)$ & $61(92,4)$ \\
\hline Keluarga Merokok & $54(81,8)$ & $12(18,2)$ \\
\hline Ayah & $45(68,2)$ & \\
\hline Ibu & $6(9,1)$ & \\
\hline Kakak & $13(19,8)$ & \\
\hline Adik & $1(1,5)$ & \\
\hline Kakek & $10(15,2)$ & \\
\hline Bergaul dengan perokok & $20(30,3)$ & $46(69,7)$ \\
\hline Riwayat Penyakit Siswa & & \\
\hline Sesak Nafas & $8(12,1)$ & $58(87,9)$ \\
\hline Sesak nafas disertai nyeri dada & $4(50)$ & $4(50)$ \\
\hline Sesak nafas disertani nafas berbunyi/mengi & $3(37,5)$ & $5(62,5)$ \\
\hline Mengalami batuk 2 minggu terakhir & $20(30,3)$ & $46(69,7)$ \\
\hline Batuk disertai dahak/reak & $12(60)$ & $8(40)$ \\
\hline $\begin{array}{l}\text { Pernah mengalami gangguan pernafasan selama } \\
\text { sekolah disini (Sesak nafas, nyeri pada dada, batuk dll) }\end{array}$ & $36(54,5)$ & $30(45,5)$ \\
\hline $\begin{array}{l}\text { Pernah mengalami gangguan pernafasan sebelum } \\
\text { sekolah disini (Sesak nafas, nyeri pada dada, batuk dll) }\end{array}$ & $29(43,9)$ & $37(56,1)$ \\
\hline
\end{tabular}

Sumber : Data Primer, 2017

trasi $\mathrm{PM}_{2,5}$ di dalam ruang kelas tertinggi di ruang kelas VIII A sebesar $34,62 \mu \mathrm{g} / \mathrm{m}^{3}$ dan terendah di ruang kelas VIII C sebesar $26,56 \mu \mathrm{g} / \mathrm{m}^{3}$. Distribusi konsentrasi $\mathrm{PM}_{2,5}$ di lingkungan sekolah SMPN 16 Bandung berdistribusi normal dengan nilai mean $29,34 \mu \mathrm{g} / \mathrm{m}^{3}$ (Tabel 4).

Pola aktivitas responden yang diukur bertujuan untuk mengetahui pola pajanan $\mathrm{PM}_{2,5} \mathrm{di}$ lingkungan sekolah SMPN 16 Bandung. Pola aktivitas terdiri dari waktu pajanan yaitu waktu siswa selama di sekolah dalam satuan hari per jam, dihitung dari mulai masuk sekolah sampai waktu pulang sekolah. Frekuensi pajanan didapatkan dari jumlah hari sekolah dalam setahun dengan satuan hari per tahun didapatkan dengan menjumlahkan total hari dalam 1 tahun dikurangi dengan hari libur sekolah, libur semester, libur hari nasional dan absen. Durasi pajanan dihitung berapa lama siswa sudah sekolah di tempat tersebut dalam satuan tahun, dihitung dari tahun awal pertama masuk sekolah sampai dengan dilaksanakan penelitian ini. Laju inhlasi didapatkan berdasarkan rumus logaritmik berat badan terhadap laju inhalasi normal yang menghasilkan persamaan : y $=5,3 \operatorname{Ln}(\mathrm{x})$ $-6,9$ dengan $\mathrm{y}=$ Laju inhalasi $\left(\mathrm{m}^{3} /\right.$ hari $)$ dan $\mathrm{x}=$ Berat badan $(\mathrm{kg}) .{ }^{10}$

Uji normalitas, diketahui bahwa variabel berat badan, frekuensi eksposure dan laju inhalasi berdistribusi tidak normal sehingga nilai yang digunakan adalah median yang secara berurutan 
adalah $47,35 \mathrm{~kg}, 0,56 \mathrm{~m}^{3} / \mathrm{jam}$, dan 220 hari/tahun. Berat badan terendah yaitu $32,20 \mathrm{~kg}$ dan tertinggi yaitu $104,40 \mathrm{~kg}$ dengan rerata berat badan seluruh siswa yaitu 49,10 kg. Untuk nilai durasi pajanan real time setiap siswa sama yaitu 1,8 tahun. Kegiatan siswa secara umum selama disekolah dibagi menjadi dua kegiatan yaitu kegiatan belajar di dalam kelas dan kegiatan istirahat di luar sekolah. Kegiatan belajar mengajar dilakukan mulai pukul 07.00 pagi sampai pukul 13.00 siang. Hanya memiliki waktu istirahat 1 kali selama 30 menit. Dapat diketahui bahwa waktu pajanan setiap siswa di sekolah sama yaitu 6 jam/hari (Tabel 4).

Dalam penelitian ini analisis Dosis referensi inhalasi $(R f C)$ dengan menurunkan batas aman yang diajukan oleh National Ambient Air Quality Standart (NAAQS) US-EPA tahun 2006 untuk $\mathrm{PM}_{2,5}$ yaitu $35 \mu \mathrm{g} / \mathrm{m}^{3}$ karena nilai default faktor-faktor antropometri pemajanan yang digunakan diketahui. Sementara baku mutu $\mathrm{PM}_{2,5}$ menurut Peraturan Menteri Lingkungan Hidup No.41 tahun 1999 tidak dapat digunakan karena nilai default pemajanan tidak diketahui. ${ }^{11-14}$ Oleh karena itu dengan konsentrasi aman, maka $I=R f C$,
Kemudian dilakukan substitusi nilai default EPA, $\mathrm{R}=0,83 \mathrm{~m}^{3} / \mathrm{jam}, \mathrm{t}_{\mathrm{E}=} 24 \mathrm{jam} / \mathrm{hari}, \mathrm{f}_{\mathrm{E}}=350$ hari $/ \mathrm{ta}-$ hun, $\mathrm{Wb}=70 \mathrm{~kg}, \mathrm{t}_{\text {avg }}=365$ hari/tahun, $\mathrm{Dt}=30$ tahun dan nilai $\mathrm{C}=$ Standar NAAQS $=35 \mu \mathrm{g} / \mathrm{m}^{3}$, didapatkan:

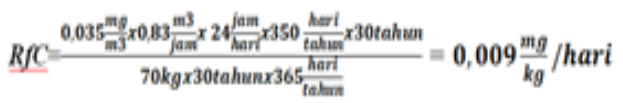

Perhitungan intake $\mathrm{PM}_{2,5}$ pada seluruh responden siswa kelas VIII digunakan pendekatan deterministic dengan single point estimate (penggunaan satu nilai) karena karakteristik responden homogen. Nilai yang digunakan tersebut dapat berupa nilai mean atau median tergantung normal atau tidaknya distribusi masing-masing variabel. Nilai konsentrasi $\mathrm{PM}_{25}$ menggunakan nilai mean sebesar $29,34 \mu \mathrm{g} / \mathrm{m}^{3}$ karena diketahui nilai data berdistribusi normal. Untuk nilai berat badan, laju inhalasi dan frekuensi pajanan menggunakan nilai median karena berdistribusi tidak normal, secara berturut-turut nilainya adalah $47,35 \mathrm{~kg}, 0,56 \mathrm{~m} 3 /$ jam dan 220 hari per tahun, Dt: 1,8 tahun; tE: 6 jam. Perbandingan nilai intake untuk setiap durasi pajanan yaitu realtime, 3 tahun dan 12 tahun secara

Tabel 3. Konsentrasi PM2,5Berdasarkan Lokasi Pengukuran

\begin{tabular}{|c|c|c|c|c|c|c|}
\hline \multirow{2}{*}{ Titik Pengukuran } & \multicolumn{6}{|c|}{ Konsentrasi $(\mu \mathrm{g} / \mathrm{m} 3)$} \\
\hline & Hasil & Mean \pm SD & Median & Min-Max & p-value *) & Distribusi \\
\hline Gerbang Masuk Depan & 49,3 & & & & & \\
\hline Lapangan Olahraga & 36,69 & & & & & \\
\hline Koridor Kelas VIII A & 16,18 & & & & & \\
\hline Koridor Kelas VIII C & 37,93 & & & & & \\
\hline Koridor Kelas VIII F & 15,73 & & & & & \\
\hline Koridor Kelas VIII I & 22,21 & $29,34 \pm 10,43$ & 27,08 & $15,75-49,30$ & 0.200 & Normal \\
\hline Ruang Kelas VIIIA & 34,62 & & & & & \\
\hline Ruang Kelas VIII C & 26,56 & & & & & \\
\hline Ruang Kelas VIII F & 26,92 & & & & & \\
\hline Ruang Kelas VIII I & 27,24 & & & & & \\
\hline
\end{tabular}

Sumber : Data Primer, 2017

Tabel 4. Karakteristik Antropometri dan Pola Aktivitas Siswa

\begin{tabular}{lccccc}
\hline \multicolumn{1}{c}{ Variabel } & Mean \pm SD & Median & Min-Max & p values & Distribusi \\
\hline Berat Badan $(\mathrm{Wb})$ & $49,10 \pm 12,11$ & 47,35 & $32,20-104,40$ & 0,00 & Tidak Normal \\
Laju Inhalasi $(\mathrm{R})$ & $0,56 \pm 0,048$ & 0,56 & $0,47-0,73$ & 0,017 & Tidak Normal \\
Frekuensi Pajanan (fE) & $219 \pm 2,34$ & 220 & $214-222$ & 0,00 & Tidak Normal \\
Durasi Pajanan real time (Dt) & & & 1,8 & & \\
Waktu Pajanan (tE) & & & 6 & & \\
\hline
\end{tabular}

Sumber : Data Primer, 2017 
berurutan adalah $8,08 \times 10^{-5} ; 1,35 \times 10^{-4} ; 5,39 \times 10^{-4}$ $\mathrm{mg} / \mathrm{kg} / \mathrm{hari}$.

Risk Quotient pada seluruh responden siswa kelas VIII SMPN 16 Bandung untuk pajanan realtime, 3 tahun dan 12 tahun secara berturut-turut adalah 0,$008 ; 0,014$ dan 0,059 . Dari nilai-nilai tersebut diketahui bahwa pada semua pajanan non karsinongenik ini dikatakan aman terhadap kesehatan karena seluruh RQ masih kurang dari satu $(\mathrm{RQ}<1)$. Manajemen risiko dilakukan apabila nilai $\mathrm{RQ}>1$. Dari hasil perhitungan estimasi risiko didapatkan nilai $\mathrm{RQ}<1$ artinya risiko kesehatan pajanan $\mathrm{PM}_{2,5}$ terhadap siswa di sekolah untuk saat ini masih aman, tetapi pajanan $\mathrm{PM}_{2,5}$ kemungkinan dapat berisiko terhadap guru dan karyawan sekolah karena mereka memiliki frekuensi pajanan dan durasi pajanan yang lebih lama dari siswa. Estimasi Intake terhadap guru dan karyawan dihitung menggunakan persamaan (3), dengan nilai $\mathrm{C}$ : $0,02934 \mathrm{mg} / \mathrm{m}^{3}$, Berat Badan $(\mathrm{Wb})=55 \mathrm{~kg}$, Laju inhalasi (R) $0,59 \mathrm{~m}^{3} / \mathrm{jam}$, frekusensi eksposure $\left(\mathrm{f}_{\mathrm{E}}\right)$ 266 hari per tahun, durasi pajanan (Dt): 44 tahun, dengan waktu pajanan $\left(\mathrm{t}_{\mathrm{F}}\right): 7$ jam. Intake pada guru dan karyawan sebesar 2,35 x 10-3 mg/kg/ hari. Perhitungan Risk Quotient untuk guru dan karyawan dengan durasi pajanan 44 tahun yaitu 0,26 . Nilai RQ untuk guru dan karyawan di SMPN 16 Bandung sebesar 0,26 masih jauh dari angka 1, dan tidak harus dilakukan manajemen risiko.

\section{PEMBAHASAN}

Hasil pengukuran konsentrasi menunjukkan terdapat 3 titik pengukuran yang melebihi baku mutu lingkungan menurut EPA tahun 2006, yaitu pada gerbang depan, lapangan olahraga dan koridor kelas VIII C dengan konsentrasi berturut-turut sebesar 49,3 $\mu \mathrm{g} / \mathrm{m}^{3}, 36,69 \mu \mathrm{g} / \mathrm{m}^{3}, 37,93 \mu \mathrm{g} / \mathrm{m}^{3}$. Jika dibandingkan dengan baku mutu berdasarkan PP No.41 Tahun 1990 konsentrasi PM $_{2,5}$ di lingkungan sekolah masih dibawah baku mutu sebesar $\left(65 \mu \mathrm{g} / \mathrm{Nm}^{3}\right)$. Konsentrasi ini cukup tinggi jika dibandingkan dengan konsentrasi $\mathrm{PM}_{2,5}$ di Universitas Payambar Azam Kampus Kedokteran Mazandaran di Sari, Iran Utara di dalam ruangan sebesar $\left(22,6 \pm 17,4 \mu \mathrm{g} / \mathrm{m}^{3}\right)$ dan di luar ruangan $\left(22,2 \pm 15,4 \mu \mathrm{g} / \mathrm{m}^{3}\right) \cdot{ }^{15}$ Kualitas udara di lingkungan sekolah sangat penting karena anak-anak sebagian besar menghabiskan waktunya di dalam kelas dan lebih rentan terhadap bahaya kesehatan akibat pengaruh kualitas udara.

Hasil pengukuran konsentrasi $\mathrm{PM}_{2,5}$ di lingkungan sekolah menurun dengan bertambahnya jarak antara titik lokasi pengukuran dengan jalan raya. Partikulat terbawa angin lebih jauh dari sumber pencemar sehingga terlihat rendah pada kawasan yang dekat dengan sumber. Partikulat akan terakumulasi dan menjadi tinggi pada jarak-jarak yang lebih jauh dimana kecepatan angin lebih rendah. ${ }^{16}$ Konsentrasi $\mathrm{PM}_{2.5}$ lebih tinggi di titik koridor kelas VIIIC disebabkan pada saat pengukuran ada aktivitas pembakaran sampah dekat dengan lokasi pengukuran.

Menurut penelitian yang dilakukan di Mexico City Metropolitan Area (MCMA) emisi pembakaran sampah menyumbang lebih dari $60 \%$ sumber utama partikulat klorida. Garbage burning (GB) menghasilkan $\mathrm{HCl}$ sampai 3 pbb di permukaan tanah terutama disebabkan oleh pembakaran polivinil klorida (PVC) di sampah dan merupakan sumber penting $\mathrm{PM}_{2.5}$ menyumbang sekitar 3-30\% rata-rata $\mathrm{PM}_{2.5}{ }^{17}$

Ada perbedaan konsentrasi $\mathrm{PM}_{2,5}$ pada koridor dan ruang kelas, diketahui konsentrasi di dalam ruang kelas lebih tinggi dibandingkan dengan di koridor. Meskipun berdasarkan hasil uji statistik tidak menunjukkan adanya perbedaan rata-rata yang signifikan (pvalue $>0,005$ ). Hubungan antara pencemaran partikulat $\left(\mathrm{PM}_{1}, \mathrm{PM}_{2,5}, \mathrm{PM}_{10}\right)$ di 12 titik indoor dan 5 titik outdoor yang diukur selama hari kerja pada pagi sampai sore hari pada Universitas Payambar Azam Kampus Kedokteran Mazandaran di Sari, Iran Utara, diketahui tidak ada perbedaan konsentrasi partikulat antara indoor dan outdoor. ${ }^{18}$ Pengukuran rata-rata konsentrasi $\mathrm{PM}_{2,5}$ di sekolah dasar gym antara ruang belajar dan udara ambien tidak berbeda jauh. ${ }^{19}$ Hal ini membuktikan bahwa tidak ada perbedaan risiko kesehatan akibat pencemaran partikulat di dalam maupun di luar ruangan pada siang hari. Berdasarkan hasil penelitian sebelumnya diketahui bahwa peningkatan konsentrasi $\mathrm{PM}_{2,5}$ sebesar $1 \mu \mathrm{g} / \mathrm{m}^{3}$ di udara luar ternyata dapat meningkatkan konsentrasi $\mathrm{PM}_{2,5}$ sebesar $0,58 \mu \mathrm{g} / \mathrm{m}^{3}$ di dalam ruang. ${ }^{20}$

Paparan konsentrasi partikel yang tinggi melebihi batas WHO di lingkungan sekolah terhadap siswa dipengaruhi oleh lokasi sekolah yang dekat jalan raya dengan kepadatan lalu lintas tinggi ditemukan di Hong Kong. ${ }^{21}$ Konsekuensi kese- 
hatan yang buruk dapat terjadi pada orang-orang yang berolahraga di area dengan polusi lingkungan yang tinggi, seperti di pusat kota besar dengan lalu lintas padat.

Berat badan responden siswa kelas VIII SMPN 16 Bandung antara 32,20 sampai 104,40 $\mathrm{kg}$ dengan nilai median adalah $49,10 \mathrm{~kg}$. Semakin kecil berat badan maka intake yang akan diterima semakin besar karena berat badan berfungsi sebagai denominator. Dalam analisis risiko berat badan akan mempengaruhi besarnya nilai risiko seseorang akibat agen pencemaran, semakin berat badan seseorang maka semakin kecil kemungkinan untuk mengalami risiko. Laju inhalasi responden disini menggunakan rumus logaritmik berat bedan $y=5,3 \ln (\mathrm{x})-6,9$, artinya laju inhlasi seseorang dipengaruhi oleh berat badan mereka. Semakin besar berat badan yang terukur maka semakin tinggi pula nilai laju inhalasinya. ${ }^{22}$

Faktor status perokok aktif dan perokok pasif juga mempengaruhi besarnya intake terhadap $\mathrm{PM}_{2,5}$ karena diketahui bahwa asap rokok dapat menjadi sumber $\mathrm{PM}_{2,5}$. Berdasarkan penelitian sebelumnya di Melbourne, Australia tahun 2007, setiap penambahan orang merokok dalam 1 meter dari monitor akan meningkatkan rata-rata konsentrasi $\mathrm{PM}_{2,5}$ sekitar $30 \%$ dan diperkirakan ratarata paparan terhadap orang yang berada setinggi atau diatas kepala perokok akan meningkat $50 \%{ }^{23}$ Survei di Semarang menunjukkan indikator kadar $\mathrm{PM}_{25}$ akan menunjukkan angka yang lebih tinggi ketika ada penambahan satu orang saja yang merokok dalam ruangan, meskipun jarak dengan alat monitor cukup jauh 2-5 meter. ${ }^{24}$

Pada saat penelitian diketahui ada 5 siswa yang sudah merokok dengan jumlah batang rokok yang dihisap sebanyak 1-2 batang per hari, sedangkan yang menjadi perokok pasif dirumahnya sebanyak 81,1\% karena ada anggota keluarganya yang merokok dan yang paling banyak adalah ayah. Perokok pasif adalah orang yang paling berisiko karena harus menerima dampak paparan asap rokok dari orang lain. Tingginya prevalensi orang yang terpapar asap rokok di Indonesia sebanding dengan tingginya prevalensi orang yang merokok. ${ }^{24}$ Artinya siswa SMPN 16 Bandung berisiko terhadap paparan $\mathrm{PM}_{2,5}$ di rumah akibat rokok.

Nilai $R f C$ yang digunakan dalam penelitian ini lebih kecil dari nilai $R f C$ pada penelitian Novirsa (2012) untuk penduduk residential di sekitar daerah kawasan industri PT Semen Padang Lubuk Kilangan Padang sebesar $0,01 \mathrm{mg} / \mathrm{kg} / \mathrm{hari}$ yang menghitung dengan pendekatan NOAEL.

Intake pajanan realtime menggambarkan besar pajanan yang telah diterima individu dari sejak mulai sekolah sampai saat dilaksanakan penelitian ini, Sedangkan intake pajajan $\mathrm{PM}_{2.5}$ selama 3 tahun adalah estimasi besar pajanan yang diterima individu selama dia bersekolah di SMPN 16 Bandung dengan masa sekolah untuk tingkat SMP umumnya adalah 3 tahun. Intake pajanan 12 tahun menggambarkan estimasi besar pajanan yang diterima oleh individu selama berstatus sebagai pelajar dihitung dari SD sampai SMA. Dari perhitungan tersebut diketahui bahwa durasi pajanan sangat berpengaruh terhadap nilai intake, semakin lama siswa berada dilokasi tersebut maka semakin besar risiko untuk mendapatkan efek merugikan kesehatan. Selain itu berdasarkan hasil perhitungan intake per individu diketahui bahwa semakin besar berat badan seseorang maka semakin kecil intake dan tingkat risikonya. Semakin besar nilai konsentrasi $\mathrm{PM}_{2,5}$ maka intake yang diterima individu semakin besar.

Intake yang diterima oleh masing-masing individu berbeda-beda, hal ini dipengaruhi oleh berat badan, frekuensi pajanan dan laju inhalasi tiap individu. Hal ini juga bisa disebabkan aktivitas setiap siswa berbeda-beda. Konsentrasi $\mathrm{PM}_{2,5}$ di dalam ruangan biasanya lebih tinggi dari pada di luar ruangan. Hal ini dipengaruhi oleh sumber partikulat dapat berasal dari asap rokok, asap dapur, dan juga sumber dari luar ruangan.

Dari hasil perhitungan intake dapat diketahui adanya pengaruh durasi pajanan terhadap intake agen pencemaran, semakin panjang durasi pajanan, maka intake $\mathrm{PM}_{2.5}$ yang diterima individu semakin besar. Kondisi ini sesuai dengan penelitian yang dilakukan Rose terhadap Polantas Polrestabes Surabaya yang menyatakan durasi pajanan yang tinggi terhadap Polantas bisa berakibat terhadap tingginya risiko keracunan dari beberapa emisi gas kendaraan bermotor. Risiko ini dapat terjadi karena pengakumulasian emisi gas kendaraan bermotor yang masuk ke dalam tubuh melalui inhalasi yang semakin lama semakin meningkat. ${ }^{22}$ Menurut Kurnia semakin lama masa kerja semakin 
banyak paparan debu $\mathrm{PM}_{25}$ maka risiko kejadian penyakit akibat paparan debu $\mathrm{PM}_{2,5}$ seperti PPOK, bronchitis kronis, emfisema, batuk, asma semakin meningkat. ${ }^{25}$

$\mathrm{PM}_{2,5}$ sendiri di dalam pernapasan memiliki risiko untuk terjadinya akumulasi di dalam pernapasan dalam khususnya bronchi dan alveoulus. Akumulasi ini disebut dengan deposisi partikel. Di dalam pernapasan $\mathrm{PM}_{2,5}$ mengalami deposisi partikel secara sedimentasi dan gerak brown. Paparan dalam ruangan terhadap partikulat halus $\left(\mathrm{PM}_{2,5}\right)$ meningkatkan gejala pernafasan pada wanita dan anak-anak pada rumah tangga berpenghasilan rendah, dan mereka yang memiliki kebiasaan merokok di dalam rumah. ${ }^{26}$

Karakteristik risiko pada siswa ditentukan dari hasil perbandingan antara nilai intake dengan nilai dosis referensi $(R f C)$, maka semakin besar intake maka akan semakin besar risikonya. Berdasarkan perhitungan risiko realtime, 3 tahun dan 12 tahun pada siswa didapatkan bahwa $\mathrm{RQ}<1$ artinya siswa kelas VIII yang menjadi sampel penelitian belum memiliki risiko kesehatan akibat dari pajanan $\mathrm{PM}_{2,5}$ di lingkungan sekolah, karena intake yang masuk ke dalam tubuh masih pada batas aman. Hasil ini berbeda dari hasil penelitian yang dilakukan oleh Abrianto di Sekolah Dasar Negeri 01 Pondok Cina, Depok bahwa pajanan $\mathrm{PM}_{10}$ di lingkungan sekolah berisiko pada semua anak sekolah. Bahkan diketahui kemungkinan siswa mendapatkan gangguan pernafasan disekolah 3,4 sampai 6,1 kali dibandingkan siswa yang intake debunya lebih rendah pada siswa SDN 01 Pondok Cina. ${ }^{10}$

Tingkat paparan $\mathrm{PM}_{2,5}$ memiliki efek lebih besar pada penerimaan rumah sakit terkait pernapasan dibandingkan tingkat $\mathrm{PM}_{10}$. Anak-anak dan orang tua adalah yang paling rentan terhadap masuknya rumah sakit untuk penyakit pernafasan. Tingkat kunjungan rawat inap rumah sakit untuk penyakit pernafasan (bronkitis akut, rhinitis alergi, dan asma) meningkat dengan meningkatnya partikulate matter dan suhu, dan dengan penurunan kelembaban relatif. Bahkan individu sehat pun terbukti memiliki pengaruh terjadinya penurunan fungsi paru setelah terpapar tingkat $\mathrm{PM}_{2,5}$ yang tinggi sesuai dengan penelitian lain $\mathrm{PM}_{2,5}$ tinggi terkait dengan risiko kejadian asma yang lebih tinggi. ${ }^{27}$
Penelitian tidak dilakukan perumusan manajemen risiko karena berdasarkan nilai risk quotient (RQ) untuk pajanan $\mathrm{PM}_{2,5}$ terhadap siswa kelas VIII untuk durasi pajanan realtime, 3 tahun, 12 tahun sekolah masih jauh dari nilai $1(\mathrm{RQ}<1)$, artinya masih dalam batas aman sehingga tidak memerlukan manajemen risiko. Bahkan estimasi risiko yang dihitung untuk guru dan karyawan yang memiliki durasi pajanan lebih lama sekitar 44 tahun juga menunjukan $\mathrm{RQ}<1$.

Pengendalian pencemaran yang dapat dilakukan untuk mengurangi konsentrasi $\mathrm{PM}_{2.5}$ di lingkungan sekolah dapat dilakukan dengan mengurangi sumber pencemar diantara memperbaiki perilaku penghuni sekolah dengan tidak merokok di lingkungan sekolah, membuka jendela dan pintu kelas setiap hari, membersihkan ruang kelas setiap hari dan tidak membakar sampah di lingkungan sekolah dan melakukan penanaman pohon di lingkungan sekolah.

Pengendalian ini juga di rekomendasikan oleh McCormack et al., dalam penelitiannya, menurutnya merokok berkaitan dengan peningkatan konsentrasi $\mathrm{PM}_{2,5}$, kegiatan penyapuan berkontribusi pada PM dalam ruangan yang lebih tinggi, Jendela terbuka dihubungkan dengan $\mathrm{PM}_{2,5}$ dalam ruangan yang jauh lebih rendah, setiap jendela yang buka lebih dari 10 menit per hari $\mathrm{PM}_{2,5}$ rata-rata $0,88 \mu \mathrm{g} / \mathrm{m}^{3}$ lebih rendah. ${ }^{20}$

Penelitian sebelumnya memperkirakan bahwa menanam rata-rata empat pohon peneduh per rumah, menyebabkan pengurangan emisi karbon tahunan (pengurangan per pohon emisi karbon sekitar $10-11 \mathrm{~kg}$ per tahun). ${ }^{28}$ Penghapusan total polusi udara tahunan oleh pohon perkotaan US diperkirakan 711.000 metrik ton ( $\$ 3,8$ miliar). Pohon palem perkotaan dapat menjadi strategi yang tepat untuk memperbaiki kualitas udara dan membantu memenuhi standar udara bersih. ${ }^{29}$

\section{KESIMPULAN DAN SARAN}

Rata-rata konsentrasi $\mathrm{PM}_{2,5}$ di lingkungan sekolah $\left(29,34 \mu \mathrm{g} / \mathrm{m}^{3}\right)$, intake realtime tertinggi pada remaja siswa dengan berat badan 32,2 $\mathrm{Kg}$ sebesar $9,25 \times 10^{-5} \mathrm{mg} / \mathrm{kg} / \mathrm{hari}$ dan terendah pada siswa dengan berat badan 104,4 kg sebesar $4,49 \times 10^{-5} \mathrm{mg} / \mathrm{kg} / \mathrm{hari}$. Rata-rata intake realtime, 3 tahun dan 12 tahun untuk seluruh siswa kelas VIII sebesar $7,53 \times 10^{-5}, 1,25 \times 10^{-4}$ dan $5,02 \times 10^{-4} \mathrm{mg} /$ 
$\mathrm{kg} /$ hari.Hasil perhitungan efek non karsinogenik seluruh siswa remaja kelas VIII pada pajanan realtime, 3 tahun dan 12tahun masih dalam kondisi aman terhadap risiko efek nonkarsinogenik pajanan $\mathrm{PM}_{2,5}$ di lingkungan sekolah $(\mathrm{RQ}<1)$. Dalam penelitian selanjutnya dapat menambah titik sampling pengukuran kualitas udara dan menambah lama waktu pengukuran tiap titiknya agar menggambarkan konsentrasi risk agent di lingkungan sekolah. Serta membedakan waktu pengukuran antara musim hujan dan musim panas.

\section{UCAPAN TERIMA KASIH}

Penelitian ini dilakukan dengan dukungan Publikasi Internasional Terindeks Tugas Akhir di Universitas Indonesia (Hibah PITTA) Universitas Indonesia, Tahun Anggaran 2017 (No. 594/UN2. R3.1/HKP.05.00/2017).

\section{DAFTAR PUSTAKA}

1. Achmadi U. Dasar-Dasar Penyakit Berbasis Lingkungan. Jakarta: Rajawali Pers; 2014.

2. WHO. Ambient Air Pollution: A Global Assessment of Exposure and Burden of Disease. 2016.

3. Miller T. Living In The Environment Edition S, editor. USA: Brooks/Cole Cengage Learning; 2007.

4. Environmental Protection Agency. Particulate Matter (PM) Basics.2016. EPA. www.epa.gov. [Online].; 2016 [cited 2017 Mei Senin. Available at: https://www.epa.gov/pm-pollution/ particulate-matter-pm-basics.

5. Minnesota Pollution Control Agency. Fine Particle Pollution. 2013. [ Diakses 23 Maret 2017]. Available at: https://www.pca.state. mn.us/sites/default/files/aq8-25.pdf.

6. Lall R. Environmental Health: Studies in the Area of Environmental Health. Obesity Fitness \& Wellness Week. 2011; 2187.

7. Maesano et. a. Poor Air Quality in Classrooms Related to Asthma and Rhinitis in Primary School Children of the French 6 Cities Study. Thorax. 2012 Agustus; 67(8):682-8.

8. Kalaisaran G. Source Apportionment of $\mathrm{PM}_{2,5}$ Particles: Influence of Outdoor Particles on Indoor Environment of Schools Using Chemical Mass Balance. Aerosol and Air Quality Research. 2017 February; 17(12).
9. Santoso M LDHP. Atmospheric Black Carbon In PM2,5 in Indonesia Cities. J Air Waste Manag Assoc. 2013 September; 63(9).

10. Abrianto. Analisis Risiko Pencemaran Partikel Debu Terhirup (PM10) Terhadap Siswa Selama Berada di Sekolah Dasar Negeri I Pondok Cina Kota Depok Jawa Barat. Skripsi Sarjana Kesehatan Masyarakat. 2004.

11. Nurilma. A. Tingkat Risiko Kesehatan Akibat Pajanan PM10 pada Populasi Berisiko di Terminal Bus Pulogadung Jakarta Timur. Skripsi Sarjana Kesehatan Masyarakat. 2014.

12. Nukman E. Analisis Risiko Kesehatan Lingkungan Pertambangan Kapur di Sukabumi, Cirebon, Tegal, Jepara dan Tulung Agung. Jurnal Ekologi Kesehatan. 2008 April; 7.

13. Sukadi. R. Analisis Risiko Kesehatan Pajanan PM10 dan SO2 di Kelapa Gading Jakarta Utara. Skripsi Sarjana Kesehatan Masyarakat. 2014.

14. Suryaman. R. Safe Area For Residential Population to Reside Near Limestone Mining: A Risk Management Approach: Wilayah Aman Bagi Pemukiman Dekat Tambang Batu Kapur:Suatu Pendekatan Manajemen Risiko. Jurnal Ekologi Kesehatan. 2014 Desember; 10.

15. Mohammadyan M. Assessment of Indoor and Outdoor Particulate Air Pollution at an Urban Background Site in Iran. Environ Monit Assess. 2017.

16. Suhariyono e. Analisis Tingkat Partikel Debu PM10 dan PM2,5 Terhadap Kesehatan Penduduk di Sekitar Pabrik Semen Citeureup Bogor. P3TM-BATAN. 2003 Juli.

17. Li G,L,BN,M. Contribution of Garbage Burning to Chloride and PM2,5 in Mexico CIty. Atmos.Chem.Phys. 2012; 12.

18. Mohammadyan M,SB. Indoor and Outdoor PM10 and PM2,5 Concentration in Primary Schools In Sari. Iran. Arhiy Za Higijenu Rada i Toksikologiju. 2013.

19. Branis M,S,IH. Exposure of Children to Airborne Particulate Matter of Different Size Franctions During Indoor Physical Education at School. Building and Environment. 2008; 44.

20. McCornack e. Common Household Activities are Associated with Elevated Particulate Mat- 
ter Concentration in Bedrooms of Inner-City Baltimore Pre School Children. Environ Res. 2008; 106(2).

21. S.C Lee MC. Indoor and Outdoor Air Quality Investigation at Schools in Hong Kong. Chemosphere. 2000.

22. Rose. Penilaian Risiko Paparan Asap Kendaraan Bermotor Pada Polantas Polrestabes Surabaya Tahun 2014. The Indonesian Journal of Occupational Safety and Health. 2014 Januari; 3.

23. Cameron $\mathrm{M}$ e. Secondhand Smoke Exposure $(\mathrm{PM} 2,5)$ in Outdoor Dining Areas and its Correlates. Epub. 2007 Februari; 19(1).

24. Nurjanah. KL,MA. Gangguan Fungsi Paru dan Kadar Cotinine Pada Urin Karyawan yang Terpapar Asap Rokok Orang Lain. KEMAS. 2014.

25. Kurnia KS. Analisis Risiko Paparan Debu PM2,5 Terhadap Kejadian Penyakit Paru Ob- struktif Kronis Pada Pekerja Bagian Boiler Perusahaan Lem di Probolinggo. Jurnal Kesehatan Lingkungan. 2014 Januari; 7.

26. Rumchev K. Health Risk Assessment of Indoor Air Quality Socioeconomic and House Characteristics on Respiratory Health among Women and Children of Tirupur, South India. Environmental Research and Public Health. 2017.

27. Hyun Young Jo e. Effects of Particulate Matter on Respiratory Disease and the Impact of Meteorological Factors in Busan Korea. Respiratory Medicine. 2017.

28. H A. Shade Trees Reduce Building Energy Use and $\mathrm{CO}_{2}$ Emissions from Power Plants. Environmental Pollution. 2002 March; 116.

29. Nowak CS. Air Pollutions Removal by Urban Trees and Shrubs in the United States. Urban Forestry \& Urban Greening. 2006 April; 4(34). 